\title{
The Optimum Position of Porous Insert for a Double-Pipe Heat Exchanger Based on Entropy Generation and Thermal Analysis
}

DOI:

10.1007/s10973-019-08362-x

\section{Document Version}

Accepted author manuscript

Link to publication record in Manchester Research Explorer

Citation for published version (APA):

Akbarzadeh, M., Rashidi, S., Keshmiri, A., \& Shokri, N. (2019). The Optimum Position of Porous Insert for a Double-Pipe Heat Exchanger Based on Entropy Generation and Thermal Analysis. Journal of Thermal Analysis and Calorimetry. https://doi.org/10.1007/s10973-019-08362-x

Published in:

Journal of Thermal Analysis and Calorimetry

\section{Citing this paper}

Please note that where the full-text provided on Manchester Research Explorer is the Author Accepted Manuscript or Proof version this may differ from the final Published version. If citing, it is advised that you check and use the publisher's definitive version.

\section{General rights}

Copyright and moral rights for the publications made accessible in the Research Explorer are retained by the authors and/or other copyright owners and it is a condition of accessing publications that users recognise and abide by the legal requirements associated with these rights.

\section{Takedown policy}

If you believe that this document breaches copyright please refer to the University of Manchester's Takedown Procedures [http://man.ac.uk/04Y6Bo] or contact uml.scholarlycommunications@manchester.ac.uk providing relevant details, so we can investigate your claim.

\section{OPEN ACCESS}




\title{
The Optimum Position of Porous Insert for a Double-Pipe Heat Exchanger Based on Entropy Generation and Thermal Analysis
}

\author{
Mohsen Akbarzadeh ${ }^{1}$, Saman Rashidi ${ }^{1}$, Amir Keshmiri $^{2 *}$ and Nima Shokri ${ }^{3}$ \\ ${ }^{1}$ Department of Mechanical Engineering, Ferdowsi University of Mashhad, Mashhad, \\ 91775-1111, Iran \\ ${ }^{2}$ School of Mechanical, Aerospace and Civil Engineering (MACE), University of Manchester, \\ Manchester M13 9PL, UK \\ ${ }^{3}$ School of Chemical Engineering and Analytical Science, University of Manchester, \\ Manchester M13 9PL, UK \\ *corresponding author e-mail: A.Keshmiri@manchester.ac.uk
}

\begin{abstract}
:
In the present paper, the first and second laws of thermodynamics are utilized to select the optimized position of porous insert to achieve maximum heat transfer and minimum pressure drop and entropy generation inside a double-pipe heat exchanger. Four different porous inserts configuration are considered in the heat exchanger, where the porous layers are placed at the core of the inner tube, wall of the inner tube, and inner or outer walls on outer tube for these cases. In addition, the effects of Darcy number and thermal conductivity of porous material on entropy generation, heat transfer enhancement and pressure drop penalty are investigated. The flow and heat transfer are modeled numerically using the finite volume approach, while for the porous layers, Darcy-Brinkman-Forchheimer model is applied to model the flow characteristics. It was found that for outer tube of a double-pipe heat exchanger, placing the porous layer in the inner wall creates larger pressure drops. For inner tube, it is better to place the porous layer at the center, while for outer one, it is better to insert the porous layer at inner wall (interface wall) to achieve the higher values of heat transfer rate. Moreover, the thermal and viscous entropy generations are more pronounced for the cases, where the porous substrate is not located at the core of the heat exchanger.
\end{abstract}


Keywords: Porous insert; double-pipe heat exchanger; Finite Volume Method; Computational Fluid Dynamics; Heat Transfer; Porous Media;

\section{Nomenclature}
A
surface area $\left(\mathrm{m}^{2}\right)$
$\mathrm{C}_{\mathrm{F}}$
Forchheimer coefficient (-)
$\mathrm{C}_{\mathrm{p}} \quad$ specific heat at constant pressure $(\mathrm{J} / \mathrm{kgK})$
$\mathrm{D}_{\mathrm{h}} \quad$ hydraulic diameter $(\mathrm{m})$
$\mathrm{Da}$
Darcy number (-)
$\mathrm{k}$
thermal conductivity $(\mathrm{W} / \mathrm{mK})$
K
permeability of the porous medium $\left(\mathrm{m}^{2}\right)$
$\mathrm{K}_{\mathrm{r}}$
thermal conductivity ratio (-)
$\mathrm{L}$
length of the heat exchanger (m)
$\mathrm{N}_{\mathrm{g}}$
dimensionless local volumetric entropy generation rate (-)
$\mathrm{N}_{\mathrm{t}}$
dimensionless total entropy generation rate (-)
$\mathrm{P}$
pressure $(\mathrm{Pa})$
$\Delta \mathrm{p}$
pressure drop $(\mathrm{Pa})$
$\operatorname{Pr}$
Prandtl number (-)
Q
power (W)
$\mathrm{r}$
radius $(\mathrm{m})$
$\mathrm{R}$
radius ratio (-)
Re Reynolds number (-)
S
thickness of the porous substrate (m)
$S_{g e n} \quad$ entropy generation rate $\left(\mathrm{W} / \mathrm{m}^{3} \mathrm{~K}\right)$
$\mathrm{T} \quad$ temperature $(\mathrm{K})$
$\mathrm{U}_{\mathrm{c}}, \mathrm{U}_{\mathrm{h}} \quad$ inlet velocity of cold and hot fluids $(\mathrm{m} / \mathrm{s})$ 
$\mathrm{u}, \mathrm{v}$ velocity component in $\mathrm{x}$ and $\mathrm{y}$ directions, respectively $(\mathrm{m} / \mathrm{s})$

$\mathrm{x}, \mathrm{y}$ rectangular coordinates components $(\mathrm{m})$

Greek symbols

$\begin{array}{ll}\alpha & \text { thermal diffusivity of the fluid }\left(\mathrm{m}^{2} / \mathrm{s}\right) \\ \varepsilon & \text { porosity }(-) \\ \mu & \text { dynamic viscosity }(\mathrm{kg} / \mathrm{ms}) \\ v & \text { kinematic viscosity }\left(\mathrm{m}^{2} / \mathrm{s}\right) \\ \rho & \text { density of the fluid }\left(\mathrm{kg} / \mathrm{m}^{3}\right) \\ \theta & \text { Non-dimensional temperature }(-) \\ \text { Subscripts/superscripts } \\ \text { eff } & \text { effective } \\ \text { c } & \text { cold } \\ \text { f } & \text { fluid } \\ \text { h } & \text { hot } \\ \text { I } & \text { inner } \\ \text { O } & \text { outer } \\ \text { R } & \text { ratio } \\ \text { S } & \text { solid } \\ 0 & \text { heat exchanger with no insert } \\ & \end{array}$

\section{Introduction}

In recent years, heat exchangers are widely utilized in various industries including thermal power plants, the oil and gas industries, air conditioning and refrigeration systems, chemical processing, polymers, etc. The high price of energy and materials together with the sustainability issues motivated many engineers to design more efficient and economical heat 
exchange devices. Thus, numerous attempts have been made to enhance the overall thermal performance of such systems [1-3].

A double-pipe heat exchanger can be used to transfer thermal energy between fluids with various temperatures. In a review article, Omidi et al. [4] presented the wide application of double-pipe heat exchangers in various industries due to their simplicity. Many groups looked into different novel approaches to improve the performance of such heat exchanges. For example, Maddah et al. [5] used $\mathrm{Al}_{2} \mathrm{O}_{3}$ /water nanofluid and twisted tapes in the doublepipes and showed experimentally that the maximum friction factor and heat transfer rate in the double-pipe with twisted tape and nanofluids are respectively 2.8 and 4 times of those obtained in a conventional tube. Iqbal et al. [6] attached the longitudinal fins to the outer wall of the inner pipe in a double-pipe and performed a numerical study to find optimal configuration, maximizing the heat transfer coefficient. They reported that $\Omega=500$ is the best choice in terms of cost, pressure drop and heat transfer coefficient, where $\Omega$ was the ratio of conductivity of the fin-pipe material to that of the fluid. Sheikholeslami and Ganji [7] investigated experimentally and numerically the effects of perforated turbulators on heat transfer enhancement in a double-pipe heat exchanger and showed that the temperature gradient decreases as the pitch ratio of turbulators increases. Anas El Maakoul et al. [8] numerically investigated the influence of helical baffles placed in the annulus side of a double-pipe heat exchanger on thermo-hydraulic performance of this device and observed a maximum of $45 \%$ increase in the convective heat transfer by using this technique. Moreover, they concluded that the maximum pressure drop is 21 times larger than that in a conventional device.

Porous materials placed in heat exchangers are believed to be one of the promising techniques to enhance the overall thermal performance of such devices. These materials are a great candidate for transferring considerable values of thermal energy inside a small region as 
they have small density, large effective surface, and large values of thermal conductivity. Some researchers used these materials in double-pipe heat exchangers to improve the thermohydraulic performance of this device. For instance, Du et al. [9] numerically investigated heat transfer in a double-pipe filled with metal foam and they found that the optimal range for the ratio of inner tube diameter to outer tube diameter to design metal foam filled double-pipe heat exchangers is 0.6-0.7. Xu et al. [10] filled the double-pipe heat exchanger with metallic foam to improve the heat transfer in this device and reported that the effectiveness of the device improves by decreasing porosity or increasing pore density. Targui and Kahalerras [11-12] placed a number of porous blocks in a double-pipe heat exchanger and showed that for the case of small values of thermal conductivity ratio, highest heat transfer occurs at small values of permeability and large values of thicknesses of the porous blocks. Alkam and AlNimr [13] partially filled a double-pipe heat exchanger by porous layers and considered only one arrangement for porous layer position in the heat exchanger. Two porous layers were attached at both sides of the inner tube and their results showed that the thermal performance of this system enhances by inserting porous layers within the heat exchanger.

In light of the results reported by previous researchers in this field, it emerges that inserting porous layer in a double-pipe heat exchanger results in a heat transfer enhancement. However, this technique has a disadvantage in increasing the pumping power required by the system. It is clear that not all the energy input into a heat exchanger can be utilized effectively and there are some irreversiblities or lost works during the process. This raises the question of how to employ enhancement techniques in order to minimize or at least reduce the overall entropy generation associated with the system operation for improving the performance of the system. To answer this question and to provide some information for designers in practical applications, one would need to detect locally the regions with high entropy generation rate. Siavashi et al. [14] numerically studied the entropy generation of 
nanofluid, flowing through a single pass annuli, partially and completely filled with porous material. They concluded that the thermal entropy generation reduces as the nanoparticle concentration or porous substrate thickness enhances. Torabi et al. [15] conducted an analytical study to investigate entropy generation in a single pass conduit partially filled with porous material and showed that the thermal conductivity of porous material has a considerable influence on the entropy generation in the conduit. Kurtbaş et al. [16] studied the forced convection heat and exergy transfer in a porous rectangular channel filled with metal foam. They found that the increase in the pore density leads to an increase in Nusselt number. Torabi et al. [17] investigated the heat transfer and entropy generation in a semiporous channel in the presence of internal heat generation. They concluded that partial filling of the channel reduces the total entropy generation. Komurgoz et al. [18] investigated the magnetic effect on entropy generation in an inclined semi-porous channel. They showed that the flow and thermal fields and also entropy generation are strongly dependent on the dimensionless characteristic parameters. Karimi et al. [19] studied the influence of exothermicity and endothermicity on temperature distribution in a semi-porous channel and concluded that the thermal behavior of the system is impacted by the heat sources in both solid and fluid phases.

Allouache and Chikh [20] performed a thermodynamic analysis for a double-pipe heat exchanger filled partially with a porous layer. They considered only one arrangement for placement of porous layer and it was attached at the inner pipe. They found that the porous layer thickness and permeability of this layer directly affect the minimization of entropy generation.

There are few studies available in the literature, which have studied a double-pipe heat exchanger filled partially with a porous layer; most publications in this field have used a full filled heat exchanger. The position of porous insert in a double-pipe heat exchanger is an 
important factor that directly affects the performance of the system. This issue has not been addressed in previous research; therefore, the current study is focused on addressing this point through a numerical study. Accordingly, the first and second laws of thermodynamics are utilized to select a suitable position for the porous insert in terms of maximizing heat transfer and minimizing pressure drop and entropy generation inside a double-pipe heat exchanger. Moreover, the effects of characteristics of porous material containing permeability and thermal conductivity on entropy generation and thermo-hydraulic behavior of system are studied.

\section{Problem Definition}

The physical model and the computational domain considered in the present research are shown in Fig. 1. This figure consists of a counter-flow double-pipe heat exchanger with inner tube radius, $\underline{r}_{i}$, the outer tube radius, $r_{o}$, and length $L$. The heat exchanger is filled partially with a packed bed porous material. The outer wall of the heat exchanger is assumed as adiabatic. Cold fluid with initial temperature $T_{c}$ and initial velocity $U_{c}=0.00286 \mathrm{~m} / \mathrm{s}$ flows through the inner tube from left to right, while hot fluid with initial temperature $T_{h}$ and initial velocity $U_{h}=0.00129 \mathrm{~m} / \mathrm{s}$ flows inside the outer tube in opposite direction. Table 1 lists the geometrical parameters and thermal conditions set in this problem. Note that $S$ indicates the thickness of porous layer. To set the computational simulations, the following assumptions are used:

- Water is considered as the working fluids in both hot and cold streams.

- A steady two-dimensional laminar flow is prescribed.

- A homogeneous and isotropic porous layer is used which is in local thermal equilibrium with the working fluid. Due to small temperature variations across the porous medium the thermal equilibrium assumption is considered in this study [21]. 
- All simulations are performed for a fixed value of Reynolds number $\mathrm{Re}=300$ for both fluids.

\section{$\underline{\text { Insert Fig. } 1 \text { here }}$}

Insert table 1 here

Four different positions are considered for porous insert in the heat exchanger shown in Fig. 2. The gray layers in this figure represent the porous layers. As shown in this figure, for the first case, the porous layers are located at the core of the inner tube and inner wall of the outer tube (case a). For the second one, the porous layers are placed around the wall of the inner tube and inner wall of the outer tube (case b). The porous layers are located at the core of the inner tube and outer wall of outer tube for third case (case c). Finally, the porous layers are attached to the wall of the inner tube and outer wall of the outer tube for last case (case $d$ ). Table 2 shows the porous layers locations in both inner and outer tubes for different cases.

\section{Insert Fig. 2 here}

$\underline{\text { Insert table } 2 \text { here }}$

\section{Computational Model}

The conservation of mass, momentum, and energy equations are used to simulate current problem.

\subsection{Governing equations}

By introducing a binary parameter $\lambda$ which is equal to 0 in clear fluid region and 1 in porous region, one set of mass conservation, momentum and energy equations are utilized in both clear fluid and porous regions.

- Continuity:

$\frac{\partial u}{\partial x}+\frac{1}{r} \frac{\partial(r v)}{\partial r}=0$

- Momentum: 
$\frac{\rho}{\varepsilon^{2}}\left(u \frac{\partial u}{\partial x}+v \frac{1}{r} \frac{\partial(r u)}{\partial r}\right)=-\frac{\partial p}{\partial x}+\frac{\mu}{\varepsilon}\left(\frac{\partial^{2} u}{\partial x^{2}}+\frac{1}{r} \frac{\partial}{\partial r}\left(r \frac{\partial u}{\partial r}\right)\right)-\lambda\left(\frac{\mu}{K}+\frac{\rho C_{F}}{\sqrt{K}} \sqrt{u^{2}+v^{2}}\right) u$

$\frac{\rho}{\varepsilon^{2}}\left(u \frac{\partial v}{\partial x}+v \frac{1}{r} \frac{\partial(r v)}{\partial r}\right)=-\frac{\partial p}{\partial r}+\frac{\mu}{\varepsilon}\left(\frac{\partial^{2} v}{\partial x^{2}}+\frac{1}{r} \frac{\partial}{\partial r}\left(r \frac{\partial v}{\partial r}\right)\right)-\lambda\left(\frac{\mu}{K}+\frac{\rho C_{F}}{\sqrt{K}} \sqrt{u^{2}+v^{2}}\right) v$

\section{- Energy:}

$\rho C_{p}\left(u \frac{\partial T}{\partial x}+v \frac{1}{r} \frac{\partial(r T)}{\partial r}\right)=k_{e f f}\left(\frac{\partial^{2} T}{\partial x^{2}}+\frac{1}{r} \frac{\partial}{\partial r}\left(r \frac{\partial T}{\partial r}\right)\right)$

where $\rho, \mu$, and $C_{p}$ are density, viscosity, and specific heat of the working fluid, respectively. For inner tube $\left(0 \leq r \leq r_{i}\right), \rho=\rho_{c}, \mu=\mu_{c}$ and $C_{p}=C_{p, c}$, while $\rho=\rho_{h}, \mu=\mu_{h}$ and $C_{p}=C_{p, h}$ for outer tube $\left(r_{i} \leq r \leq r_{o}\right)$. The subscripts "c" and "h" denote the cold and hot fluids, respectively. In addition, $K$ and $\varepsilon$ denote permeability and porosity of the porous layers, respectively. The volume-averaged liquid speed $(\vec{V})$ within the porous substrate is relevant to the Darcy speed $(\vec{v})$ by Dupuit-Forchheimer equation $(\vec{v}=\varepsilon \vec{V})$. Moreover, $C_{F}$ and $K$ are Forchheimer coefficient and permeability given by [22]:

$$
\begin{aligned}
& C_{F}=\frac{1.75}{\sqrt{150 \varepsilon^{3}}} \\
& K=\frac{\varepsilon^{3} \cdot d_{p}^{2}}{180(1-\varepsilon)^{2}}
\end{aligned}
$$

The effective thermal conductivity denoted by $k_{\text {eff }}$ is calculated as [14]:

$k_{e f f}=\varepsilon k_{f}+(1-\varepsilon) k_{s}$

The non-dimensional form of the above equations are fully described in the Appendix A.

\subsection{Boundary Conditions}

The following boundary conditions are prescribed for this problem:

- At the inlet of inner pipe and outlet of outer pipe:

$$
x=0,\left\{\begin{array}{l}
0<r<r_{i}: u=U_{c}, v=0, T=T_{c} \\
r_{i}<r<r_{o}: \frac{\partial u}{\partial x}=\frac{\partial v}{\partial x}=\frac{\partial T}{\partial x}=0
\end{array}\right.
$$

- At the centerline: 
$0<x<L, r=0, \frac{\partial u}{\partial r}=0, v=0, \frac{\partial T}{\partial r}=0$

- At the outer wall of the outer pipe (adiabatic wall):

$0<x<L, r=r_{o}, u=v=0, \frac{\partial T}{\partial r}=0$

- At the inner wall of the outer pipe:

$$
0<x<L, r=r_{i}, \begin{cases}\left(\frac{\partial T}{\partial r}\right)_{c}=\left(\frac{\left(k_{e f f}\right)_{h} \partial T}{\left(k_{f}\right)_{c} \partial r}\right)_{h} & \text { case }(a) \\ \left(\frac{\partial T}{\partial r}\right)_{h}=\left(\frac{\left(k_{e f f}\right)_{c} \partial T}{\left(k_{e f f}\right)_{h} \partial r}\right)_{c} & \text { case }(b) \\ \left(\frac{\partial T}{\partial r}\right)_{h}=\left(\frac{\partial T}{\partial r}\right)_{c} & \text { case }(c) \\ \left(\frac{\partial T}{\partial r}\right)_{h}=\left(\frac{\left(k_{e f f}\right)_{c} \partial T}{\left(k_{f}\right)_{h} \partial r}\right)_{c} & \text { case }(d)\end{cases}
$$

- At the outlet of inner pipe and inlet of the outer pipe:

$$
x=L,\left\{\begin{array}{l}
0<r<r_{i}: \quad \frac{\partial u}{\partial x}=\frac{\partial v}{\partial x}=\frac{\partial T}{\partial x}=0 \\
r_{i}<r<r_{o}: u=-U_{h}, v=0, T=T_{h}
\end{array}\right.
$$

- At the interface of the clear fluid and porous region:

$$
\begin{aligned}
& u_{f}=u_{p}, v_{f}=v_{p} \\
& \left(\frac{1}{\varepsilon}\left(\frac{\partial u}{\partial r}+\frac{\partial v}{\partial x}\right)\right)_{p}=\left(\frac{\partial u}{\partial r}+\frac{\partial v}{\partial x}\right)_{f} \\
& \left(\frac{1}{\varepsilon}\left(\frac{\partial v}{\partial r}\right)\right)_{p}=\left(\frac{\partial v}{\partial r}\right)_{f} \\
& T_{f}=T_{p} \\
& \left(k_{e f f}\left(\frac{\partial T}{\partial r}\right)\right)_{p}=\left(k_{f}\left(\frac{\partial T}{\partial r}\right)\right)_{f}
\end{aligned}
$$

\subsection{Parameter Definitions}

Overall heat transfer coefficient for a counter flow double-pipe heat exchanger is defined by:

$U=\frac{Q}{A \cdot \Delta T_{m}}$

where A denotes the total surface of the inner tube. 
The logarithmic average temperature difference used for designing the heat exchanger is defined by:

$\Delta T_{m}=\frac{\Delta T_{1}-\Delta T_{2}}{\ln \frac{\Delta T_{1}}{\Delta T_{2}}}$

where,

$\Delta T_{1}=\left(T_{h, i}-T_{c, o}\right)$

$\Delta T_{2}=\left(T_{h, o}-T_{c, i}\right)$

where, subscripts $\mathrm{i}$ and o show the inlet and outlet sections of heat exchanger, respectively. Moreover, Q can be defined by:

$Q=\dot{m}_{c} \cdot C_{p, c}\left(T_{c, o}-T_{c, i}\right)=\dot{m}_{h} \cdot C_{p, h}\left(T_{h, i}-T_{h, o}\right)$

Local volumetric thermal entropy generation is defined as [23]:

$S_{g e n, t h}=\left\{\begin{array}{lr}\frac{k}{T_{i n}^{2}}\left(\nabla T^{2}\right) & \text { clear region } \\ \frac{k_{e f f}}{T_{i n}^{2}}\left(\nabla T^{2}\right) & \text { porous region }\end{array}\right.$

Local volumetric viscous entropy generation rate can be expressed as [23]:

$$
S_{\text {gen }, f}= \begin{cases}\frac{\mu}{T_{i n}}\left\{2\left[\left(\frac{\partial v}{\partial r}\right)^{2}+\left(\frac{v}{r}\right)^{2}+\left(\frac{\partial u}{\partial x}\right)^{2}\right]+\left[\frac{\partial v}{\partial x}+\frac{\partial u}{\partial r}\right]^{2}\right\} & \text { clear region } \\ \frac{\mu}{T_{i n}}\left\{2\left[\left(\frac{\partial v}{\partial r}\right)^{2}+\left(\frac{v}{r}\right)^{2}+\left(\frac{\partial u}{\partial x}\right)^{2}\right]+\left[\frac{\partial v}{\partial x}+\frac{\partial u}{\partial r}\right]^{2}\right\}+\frac{\mu}{K T_{\text {in }}}[\vec{V}]^{2} & \text { porous region }\end{cases}
$$

The ratio of overall heat transfer coefficient, thermal and viscous entropy generations for all considered cases to an unfilled heat exchanger without porous substrates are defined by:

$U_{r}=\frac{U}{U_{0}}$

$\left(S_{g e n, f}\right)_{r}=\frac{S_{g e n, f}}{S_{g e n, f, 0}}$

$\left(S_{g e n, t h}\right)_{r}=\frac{S_{g e n, t h}}{S_{g e n, t h, 0}}$

Also, the thermal conductivity ratio and pressure drop ratio are defined by: 
$k_{r}=\frac{k_{s}}{\left(k_{f}\right)_{c}}$

$\Delta P_{r}=\frac{\Delta P}{\Delta P_{0}}$

where, $\Delta P$ and $\Delta P_{0}$ are pressure drop in cases (a-d) and in unfilled heat exchanger, respectively.

\subsection{Numerical Method}

A pressure-based technique is utilized to solve the governing equations with the related boundary conditions given its suitability for incompressible flows at low velocities. Staggered grids scheme is considered for storing the pressure term at the center of cell. However, the velocity term can be stored at the cell faces for this scheme. A SIMPLE (Semi-Implicit Method for Pressure Linked Equations) algorithm is applied to couple the pressure and velocity terms. Second-Order Upwind technique is used to discretize all constitutive equations. Finally, the convergence criteria is passed when the summation of residuals are smaller than $10^{-6}$ for all the equations. All simulations are performed by Ansys-Fluent software.

\subsection{Grid Independency and Validations}

The heat exchanger is meshed by applying quadrilateral elements with structured distribution as shown in Fig. 3(a). A grid independency test was conducted here by considering four different mesh refinement levels for case (a). For each grid number, the relevant values of overall heat transfer coefficient is calculated and presented in Fig. 3(b). As shown in this figure, the percentage difference between grid numbers of $80 \times 1500$ and $110 \times 2000$ is less than $0.1 \%$. As a result, the mesh with $85 \times 1500$ cells has been used for the present computations.

\section{Insert Fig. 3 here}


In order to evaluate the accuracy of the numerical method, the current numerical results are compared with the analytical and experimental studies published in the literature. The results of this comparison are shown in Fig. 4. Fig. 4(a) shows the comparison between the current results and analytical data reported by Ucar et al. [24] for axial velocity profile in a duct partially filled by a porous layer at $\varepsilon=0.86$ and $\mathrm{K}=6.02 \times 10^{-7}$. As shown in this figure, there is an excellent agreement between the two sets of results. Moreover, Fig. 4(b) presents a comparison between the current numerical results and experimental data reported by Dukhan et al. [25] for local Nusselt number in a tube filled by porous material made by aluminum alloy 6101-T6 with porosity of $87.6 \%$. The results in this figure are presented for a velocity of $0.0058 \mathrm{~m} / \mathrm{s}$ at the inlet section of the tube. This figure shows a maximum $15 \%$ error between the numerical and experimental results.

\section{$\underline{\text { Insert Fig. } 4 \text { here }}$}

\section{Results and Discussion}

The results of numerical simulations are presented in this section for different variables including porous layer positions, thermal conductivity ratio, and Darcy number.

\subsection{Hydrodynamics}

Fig. 5(a) and 5(b) show the normalized axial velocity profile for all porous layer positions at $\mathrm{Da}=10^{-4}$ and $\mathrm{x}=\mathrm{L} / 2$. It should be noted that these profiles are presented only for the top half of the heat exchanger due to the geometrical symmetry. As can be seen in Fig. 5(a) for inner tube, the maximum axial velocity increases by placing the porous layer around the wall of the inner tube (cases (b) and (d)) in comparison with the case of unfilled heat exchanger. Note that the maximum velocity occurs on the centerline for these cases. However, the velocity peak is found in the region between the porous layer and tube wall when the porous layer is placed in the core of the heat exchanger (cases (a) and (c)). It should be stated that more flow can be pushed towards clear region with less resistance by partially filling the heat exchanger, 
which causes an enhancement in the maximum velocity. The velocity near the wall increases for these cases where the main heat transfer takes place. Fig. 5(b) shows the axial velocity profile for outer tube, where it can be observed that the maximum axial velocity increases by placing the porous layer around both walls of the outer tube (i.e., cases (a-d)) when compared to an unfilled heat exchanger.

Fig. 5(c) shows the normalized velocity profile for case (c), obtained at $x=L / 2$ and two values of Darcy number, compared with the reference case (i.e., unfilled heat exchanger). For smaller values of Darcy number or permeability, the flow tends to skew towards the clear region with less resistance, which causes an enhancement in the maximum velocity. Moreover, the axial velocity in the porous layer is nearly zero as the flow retards by the microscopic viscous and inertial forces created by the porous solid matrix.

\section{$\underline{\text { Insert Fig. } 5 \text { here }}$}

Fig. 6 plots the variations of pressure drop ratio with Darcy numbers for all porous layer positions. Note that the pressure drop ratio is defined as the ratio of the pressure drop in porous heat exchanger to that in the unfilled one. The locations of porous layer in inner pipe are the same for cases (a) and (c) and/or for cases (b) and (d). Thus, the pressure drop in the inner tube would be identical for these cases. Similar justifications can be extended to the outer pipe. It can be seen that the pressure drop increases in the heat exchanger by adding the porous layer. This is due to the high macroscopic and microscopic shear, and high bulk and microscopic inertial drag forces created by the porous medium. For the inner tube, cases (b) and (d) result in significantly higher pressure drop in comparison to the cases (a) and (c). This could be associated with the fact in cases (b) and (d), the porous layer is attached to the inner tube wall, while for cases (a) and (c), this layer is placed at the center. Therefore, due to the no slip condition at the walls, placing a porous layer at the inner tube wall would further intensify the pressure drop within this region. For the outer tube, cases (c) and (d) result in 
higher pressure drop compared to the cases (a) and (b). For cases (a) and (b), the porous layer is attached to the inner wall of the tube, while this layer is placed at the outer wall of the tube for cases (c) and (d). As a result, for outer tube, placing the porous layer in the outer wall would create higher pressure losses. It should be noted that the differences between pressure drop ratios are insignificant at higher values of Darcy number.

\section{Insert Fig. 6 here}

\subsection{First law of thermodynamics analyses}

Fig. 7 shows the effects of Darcy number and thermal conductivity ratio on the overall heat transfer coefficient ratio for all the present cases. Note that the overall heat transfer coefficient ratio is defined as the ratio of the overall heat transfer coefficient in partially filled porous heat exchangers to that in the unfilled one. Generally, the overall heat transfer coefficient ratio increases in a heat exchanger by inserting the porous layer in comparison with the unfilled one for values of the overall heat transfer coefficient ratio greater than unity. It should be stated that the overall heat transfer coefficient ratio is mainly dependent on the position of porous insert in the double-pipe heat exchanger. High thermal conductivity of a porous layer placed at the interface wall between two tubes (cases (a), (b), (d)) causes an increase in the heat transfer rate as this wall is the main region for transferring the thermal energy between two tubes. However, increase in flow velocity near the interface wall due to the presence of the porous layer at the center of inner tube or at outer wall of outer tube (cases (c), (b), (d)) is the main reason for increasing the heat transfer rate. The influence of Darcy number on overall heat transfer coefficient ratio is completely different for these cases. In case (c) where the porous substrate is not located at the interface wall, decreasing Darcy number causes an increase in the heat transfer coefficient, since smaller values of permeability cause the flow to escape to outer region and decrease the boundary layer thickness. However, in other cases (cases (a), (b), and (d)), where the porous substrate is 
placed at the interface wall for one or both of tubes, increasing Darcy number or inserting a more permeable porous layer leads to increase of overall heat transfer coefficient ratio. Note that placing a porous substrate with higher values of permeability at interface wall leads to better contact of tube surface and fluid, which causes a higher heat transfer rate. It is worth mentioning that for case (b), increasing the Darcy number has a considerable influence on heat transfer improvement as two porous layers are attached to the interface wall. Among all cases, case (a) provides the highest heat transfer rate, followed by the case (c). For example, the overall heat transfer coefficient increases by about $41 \%$ for case (a) at $\mathrm{Da}=10^{-3}$ and $\mathrm{k}_{\mathrm{r}}=100$ in comparison with the unfilled heat exchanger. Consequently, for the inner tube, it is suggested to place the porous layer at the center, while for outer one, it is recommended to insert the porous layer at inner wall (interface wall) to achieve the higher values of heat transfer rate.

The overall heat transfer coefficient ratio increases as the thermal conductivity ratio increases for all porous layer positions except for case (c). Note that for case (c), the porous substrate is not located at the interface wall and thus, the change of the thermal conductivity ratio does not have a considerable effect on the heat transfer rate. It can be seen that for lower values of the thermal conductivity ratio, case (c) has the maximum values of the overall heat transfer coefficient ratio among all cases. Note that for other cases, where the porous substrate is placed at the interface wall, inserting a porous layer with low values of the thermal conductivity ratio causes a decrease in the heat transfer rate. However, it is case (a) that provides the highest heat transfer rate among all cases for higer values of the thermal conductivity ratio. For example, the overall heat transfer coefficient increases by about $35 \%$ for case (c) at $\mathrm{Da}=10^{-4}$ and $\mathrm{Kr}=10$, when compared to the unfilled heat exchanger. This coefficient increases by about $44 \%$ for case (a) at $\mathrm{Da}=10^{-4}$ and $\mathrm{k}_{\mathrm{r}}=200$ in comparison with the unfilled heat exchange. 


\section{Insert Fig. 7 here}

\subsection{Second law of thermodynamics analyses}

Fig. 8 shows the thermal entropy generation contours for all porous layer positions at $\mathrm{k}_{\mathrm{r}}=100$ and $\mathrm{Da}=10^{-4}$. The contours are presented only for the top half of the heat exchanger due to the symmetry in the geometric configuration. In this figure, the thermal entropy generation is zero for the top and bottom sections of the domain in all cases. The top wall of the heat exchanger and symmetrical centreline in the bottom represent insulated surfaces. For an unfilled heat exchanger, the maximum value of thermal entropy generation is found near the interface between the two tubes, where the maximum heat transfer and temperature gradients occur. For double-pipe heat exchangers partially filled with porous material it can be seen that the maximum value of thermal entropy generation can occur near the interface between the two tubes or at the interface of the porous and clear regions depending on the location of porous material.

\section{Insert Fig. 8 here}

Fig. 9 displays the viscous entropy generation contours for all porous layer positions at $\mathrm{Da}=10^{-4}$ and $\mathrm{k}_{\mathrm{r}}=100$. It can be seen that the maximum viscous entropy generation occurs inside the inner tube, through which, the cold fluid flows. A cold fluid would generate higher viscous entropy due to a higher value of viscosity compared to the hot fluid. Moreover, the viscous entropy generation is lower inside the porous layers for all cases as the liquid velocity and velocity gradients in the porous layer are smaller than those in the clear fluid region. By attaching the porous layer inside the heat exchanger, the viscous entropy generation increases in the regions outside of the porous layer (clear fluid regions). One should note that the fluid velocity increases in the clear fluid region by placing the porous layer, which restricts the cross-sectional area for the flow, which leads to larger values of the viscous entropy 
generation. The interface between clear fluid and porous regions and heat exchanger walls are locations with higher values of viscous entropy generations.

\section{Insert Fig. 9 here}

Fig. 10(a) and 10(b) show the effects of the Darcy number and the thermal conductivity ratio on the thermal entropy generation ratio for all four cases. In Fig. 10(a), it can be seen that due to the very smooth changes in temperature gradient with the change in Darcy number for $\mathrm{Da}<10^{-4}$, the variations of the thermal entropy generation is more visible in the range $10^{-4}<\mathrm{Da}<10^{-3}$. Moreover, the thermal entropy generation increases with an increase in the thermal conductivity ratio for all cases with an exception for case (c), where changing $k_{r}$ has no obvious effects on the thermal entropy generation. Fig. 10(b) also shows that higher levels of thermal entropy are generated in cases (b) and (d). In both cases, the porous substrate is not located at the core of the inner tube of the heat exchanger. Fig. 10(c) shows the variations of viscous entropy generation ratio with the Darcy number for cases (a) and (b) (these cases have been chosen here since it was seen that the viscous entropy generation is dominant in inner tube and the position of porous layer inside the inner tube is identical for cases (a) and (c) or cases (b) and (d)). It can be seen that the viscous entropy generation increases as the Darcy number decreases. It should be noted that the velocity of the fluid in porous medium reduces for lower values of Darcy number as there are more obstructions in a porous matrix with low permeability. This leads to higher viscous dissipation and fluid friction in the porous medium. It can also be seen that in case (b) viscous entropy generation is more inside the domain in comparison to case (a). Most of the viscous dissipation in an unfilled tube is found near the walls due to the no slip condition. Placing a porous layer at the tube walls intensifies the viscous dissipation at this region and creates higher rate of viscous entropy generation. Finally, by comparing the order of the thermal and viscous entropy generations, it can be seen that the thermal entropy generation is dominant as the flow regime is laminar, where velocity 
gradients are low. It is recommended to place a porous layer at the core of the inner tube due to the high value of overall heat transfer coefficient and low value of entropy generation. For outer tubes, placing the porous layer at the interface wall creates lower values of entropy generation. From the first law of thermodynamics, one could conclude that it would be better to place the porous layer at the outer wall of the outer tube for low values of thermal conductivity ratio, while it is suggested to insert the porous layer at the interface wall of the outer tube for high values of thermal conductivity ratio.

\section{Insert Fig. 10 here}

\section{Conclusions}

In the current research, the first and second laws of thermodynamics were utilized to select an appropriate position of porous insert to maximize the heat transfer and minimize the pressure drop and entropy generation inside a double-pipe heat exchanger. Four different positions were considered for porous layer in the heat exchanger, where the porous layers were placed at the core of the inner tube, wall of the inner tube, and inner or outer walls on outer tube. The effects of the Darcy number and thermal conductivity of the porous material on entropy generation, heat transfer and pressure drop were studied. The main findings to emerge from this research are as follows:

- For smaller values of the Darcy number or permeability, more flow is diverted towards the clear region with less resistance, which causes an increase in the maximum velocity.

- For the outer tube of a double-pipe heat exchanger, placing the porous layer in the outer wall creates higher pressure drop in comparison with the inner wall. For the inner tube, inserting the porous layer in the tube wall creates higher values of pressure drop in comparison with the case with porous layer at the core. 
- For the inner tube, it is recommended to place the porous layer at the center, while for the outer one, our results suggest to place the porous layer at the outer wall of the outer tube for low values of thermal conductivity ratio, while the porous layer should be inserted at the interface wall of the outer tube for high values of thermal conductivity ratio.

- For cases where the porous substrate is placed at the interface wall, inserting a porous layer with low values of the thermal conductivity ratio leads to a decrease in the heat transfer rate.

- The overall heat transfer coefficient increases by about $44 \%$ for case (a) (i.e. the porous layers located at the core of the inner tube and inner wall of the outer tube) at $\mathrm{Da}=10^{-4}$ and $\mathrm{k}_{\mathrm{r}}=200$ in comparison with the unfilled heat exchange.

- Higher thermal entropy generation is found for the cases where the porous substrate is not located at the core of the heat exchanger.

- By attaching the porous layer inside the heat exchanger, the viscous entropy generation increases in the regions outside of the porous layer (i.e. clear fluid regions).

- The main viscous entropy generation is found inside the inner tube and its value inside the outer tube is very small in comparison with the inner tube.

- Placing a porous layer at the walls creates higher rate of viscous entropy generation in comparison to the core region.

- The thermal entropy generation is dominant as the flow regime is laminar, where the velocity gradients are generally low.

\section{Appendix A.}


The equations (1-4) can be converted to non-dimensional form by applying the following parameters:

$$
\begin{aligned}
& X=\frac{x}{r_{i}}, R=\frac{r}{r_{i}}, U=\frac{u}{U_{c}}, V=\frac{v}{U_{c}}, \theta=\frac{T-T_{c}}{T_{h}-T_{c}}, P=\frac{p}{\rho_{c} U_{c}^{2}}, \rho_{r}=\frac{\rho_{h}}{\rho_{c}}, U_{1}=\frac{U_{h}}{U_{c}} \\
& R_{1}=\frac{r_{o}-r_{i}}{r_{i}}, R_{k, c}=\frac{\left(k_{e f f}\right)_{c}}{\left(k_{f}\right)_{c}}, R_{k, h}=\frac{\left(k_{e f f}\right)_{h}}{\left(k_{f}\right)_{h}}, D a=\frac{K}{r_{i}^{2}}
\end{aligned}
$$

The governing equations in non-dimensional form can be presented as follows:

3.1.1.1 Inner tube $(0 \leq R \leq 1)$ :

$$
\begin{aligned}
& \frac{\partial U}{\partial X}+\frac{1}{R} \frac{\partial(R V)}{\partial R}=0 \\
& \frac{1}{\varepsilon^{2}}\left(U \frac{\partial U}{\partial X}+V \frac{1}{R} \frac{\partial(R U)}{\partial R}\right)=-\frac{\partial P}{\partial X}+\frac{2}{\varepsilon \cdot R e_{c}}\left(\frac{\partial^{2} U}{\partial X^{2}}+\frac{1}{R} \frac{\partial}{\partial R}\left(R \frac{\partial U}{\partial R}\right)\right) \\
& \quad-\lambda\left(\frac{2}{R e_{c} \cdot D a}+\frac{C_{F}}{\sqrt{D a}} \sqrt{U^{2}+V^{2}}\right) U \\
& \frac{1}{\varepsilon^{2}}\left(U \frac{\partial V}{\partial X}+V \frac{1}{R} \frac{\partial(R V)}{\partial R}\right)=-\frac{\partial P}{\partial R}+\frac{2}{\varepsilon \cdot R e_{c}}\left(\frac{\partial^{2} V}{\partial X^{2}}+\frac{1}{R} \frac{\partial}{\partial R}\left(R \frac{\partial V}{\partial R}\right)\right) \\
& \quad \lambda\left(\frac{2}{R e_{c} \cdot D a}+\frac{C_{F}}{\sqrt{D a}} \sqrt{U^{2}+V^{2}}\right) V \\
& \left(U \frac{\partial \theta}{\partial X}+V \frac{1}{R} \frac{\partial(R \theta)}{\partial R}\right)=\frac{2\left(\lambda\left(R_{k, c}-1\right)+1\right)}{R e_{c} \cdot P r_{C}}\left(\frac{\partial^{2} \theta}{\partial X^{2}}+\frac{1}{R} \frac{\partial}{\partial R}\left(R \frac{\partial \theta}{\partial R}\right)\right)
\end{aligned}
$$

3.1.1.2 Outer tube $\left(1 \leq R \leq \frac{r_{o}}{r_{i}}\right)$ :

$$
\begin{aligned}
& \frac{\partial U}{\partial X}+\frac{1}{R} \frac{\partial(R V)}{\partial R}=0 \\
& \frac{1}{\varepsilon^{2}}\left(U \frac{\partial U}{\partial X}+V \frac{1}{R} \frac{\partial(R U)}{\partial R}\right)=-\frac{1}{\rho_{r}} \frac{\partial P}{\partial X}+\frac{2 R_{1} U_{1}}{\varepsilon \cdot R e_{h}}\left(\frac{\partial^{2} U}{\partial X^{2}}+\frac{1}{R} \frac{\partial}{\partial R}\left(R \frac{\partial U}{\partial R}\right)\right) \\
& \quad-\lambda\left(\frac{2 R_{1} U_{1}}{R e_{h} \cdot D a}+\frac{C_{F}}{\sqrt{D a}} \sqrt{U^{2}+V^{2}}\right) U
\end{aligned}
$$




$$
\begin{gathered}
\frac{1}{\varepsilon^{2}}\left(U \frac{\partial V}{\partial X}+V \frac{1}{R} \frac{\partial(R V)}{\partial R}\right)=-\frac{1}{\rho_{r}} \frac{\partial P}{\partial R}+\frac{2 R_{1} U_{1}}{\varepsilon \cdot R e_{h}}\left(\frac{\partial^{2} V}{\partial X^{2}}+\frac{1}{R} \frac{\partial}{\partial R}\left(R \frac{\partial V}{\partial R}\right)\right) \\
-\lambda\left(\frac{2 R_{1} U_{1}}{R e_{h} \cdot D a}+\frac{C_{F}}{\sqrt{D a}} \sqrt{U^{2}+V^{2}}\right) V \\
\left(U \frac{\partial \theta}{\partial X}+V \frac{1}{R} \frac{\partial(R \theta)}{\partial R}\right)=\frac{2 R_{1} U_{1}\left(\lambda\left(R_{k, h}-1\right)+1\right)}{R e_{h} \cdot P r_{h}}\left(\frac{\partial^{2} \theta}{\partial X^{2}}+\frac{1}{R} \frac{\partial}{\partial R}\left(R \frac{\partial \theta}{\partial R}\right)\right)
\end{gathered}
$$

where $D a, P r$, and $R e$ are Darcy, Prandtl, and Reynolds numbers, respectively, given by:

$$
D a=\frac{K}{r_{i}^{2}}, P r_{c}=\frac{\mu_{c} C_{p, c}}{k_{c}}, P r_{h}=\frac{\mu_{h} C_{p, h}}{k_{h}}, R e_{c}=\frac{2 \rho_{c} U_{c} r_{i}}{\mu_{c}}, R e_{h}=\frac{2 \rho_{h} U_{h}\left(r_{o}-r_{i}\right)}{\mu_{h}}
$$

\section{References}

[1] R. Hosseinnejad, M. Hosseini, M. Farhadi, "Turbulent heat transfer in tubular heat exchangers with twisted tape." Journal of Thermal Analysis and Calorimetry, (2018) https://doi.org/10.1007/s10973-018-7400-y.

[2] H. Khajeh Arzani, A. Amiri, H. Khajeh Arzani, S. Bin Rozali, S. N. Kazi, A. Badarudin, "Toward improved heat transfer performance of annular heat exchangers with water/ethylene glycol-based nanofluids containing graphene nanoplatelets." Journal of Thermal Analysis and Calorimetry, 126 (2016) 1427-1436.

[3] A. Chumpia, K. Hooman, "Performance of tubular aluminum foam heat exchangers in multiple row bundles." Journal of Thermal Analysis and Calorimetry, (2018) https://doi.org/10.1007/s10973-018-7348-y.

[4] M. Omidi, M. Farhadi, M. Jafari, “A comprehensive review on double pipe heat exchangers.” Applied Thermal Engineering, 110 (2017) 1075-1090.

[5] H. Maddah, M. Alizadeh, N. Ghasemi, S. Rafidah Wan Alwi, "Experimental study of $\mathrm{Al}_{2} \mathrm{O}_{3}$ /water nanofluid turbulent heat transfer enhancement in the horizontal double pipes fitted with modified twisted tapes." International Journal of Heat and Mass Transfer, 78 (2014) 1042-1054. 
[6] Z. Iqbal, K.S. Syed, M. Ishaq, "Fin design for conjugate heat transfer optimization in double pipe.” International Journal of Thermal Sciences, 94 (2015) 242-258.

[7] M. Sheikholeslami, D.D. Ganji, "Heat transfer improvement in a double pipe heat exchanger by means of perforated turbulators.” Energy Conversion and Management, 127 (2016) 112-123.

[8] A. El Maakoul, A. Laknizi, S. Saadeddine, A.B. Abdellah, M. Meziane, M. El Metoui, "Numerical design and investigation of heat transfer enhancement and performance for an annulus with continuous helical baffles in a double-pipe heat exchanger." Energy Conversion and Management, 133 (2017) 76-86.

[9] Y.P. Du, Z.G. Qu, C.Y. Zhao, W.Q. Tao, "Numerical study of conjugated heat transfer in metal foam filled double-pipe.” International Journal of Heat and Mass Transfer, 53 (2010) 4899-4907.

[10] H.J. Xu, Z.G. Qu, W.Q. Tao, "Numerical investigation on self-coupling heat transfer in a counter-flow double-pipe heat exchanger filled with metallic foams." Applied Thermal Engineering, 66 (2014) 43-54.

[11] N. Targui, H. Kahalerras, "Analysis of fluid flow and heat transfer in a double pipe heat exchanger with porous structures." Energy Conversion and Management, 49 (2008) $3217-3229$.

[12] N. Targui, H. Kahalerras, "Analysis of a double pipe heat exchanger performance by use of porous baffles and pulsating flow.” Energy Conversion and Management, 76 (2013) $43-54$

[13] M.K. Alkam, M.A. Al-Nimr, "Improving the performance of double-pipe heat exchangers by using porous substrates." International Journal of Heat and Mass Transfer, 42 (1999) 3609-3618. 
[14] M. Siavashi, H.R. Talesh Bahrami, H. Saffari, "Numerical investigation of flow characteristics, heat transfer and entropy generation of nanofluid flow inside an annular pipe partially or completely filled with porous media using two-phase mixture model.” Energy, 93 (2015) 2451-2466.

[15] M. Torabi, N. Karimi, K. Zhang, G.P. Peterson, "Generation of entropy and forced convection of heat in a conduit partially filled with porous media-Local thermal nonequilibrium and exothermicity effects.” Applied Thermal Engineering, 106 (2016) 518-536.

[16] I. Kurtbas, N. Celik, I. Dinçer, "Exergy transfer in a porous rectangular channel”, Energy, 35 (2010) 451-460.

[17] M. Torabi, N. Karimi, K. Zhang, "Heat transfer and second law analyses of forced convection in a channel partially filled by porous media and featuring internal heat sources", Energy, 93 (2015) 106-127.

[18] G. Komurgoz, A. Arikoglu, I. Ozkol, "Analysis of the magnetic effect on entropy generation in an inclined channel partially filled with a porous medium", Numerical Heat Transfer, Part A, 61 (2012) 786-799.

[19] N. Karimi, D. Agbo, A. Talat Khan, P.L. Younger, "On the effects of exothermicity and endothermicity upon the temperature fields in a partially-filled porous channel", International Journal of Thermal Sciences, 96 (2015) 128-148.

[20] N. Allouache, S. Chikh, "Second law analysis in a partly porous double pipe heat exchanger.” Journal of Applied Mechanics, 73 (2006) 60-65.

[21] W. J. Minkowycz, A. Haji-Sheikh, K. Vafai, “On departure from local thermal equilibrium in porous media due to a rapidly changing heat source: the Sparrow number”, International Journal of Heat and Mass Transfer, 42 (18) (1999) 33733385. 
[22] M. Akbarzadeh, M. J. Maghrebi, "Combined effects of corrugated walls and porous inserts on performance improvement in a heat exchanger channel”, International Journal of Thermal Sciences, 127 (2018) 266-276.

[23] Ingham DB, Pop I. Transport phenomena in porous media III, vol. 3. Elsevier; 2005.

[24] E. Ucar, M. Mobedi, I. Pop, "Effect of inserted porous layer located at a wall of a parallel plate channel on forced convection heat transfer", Transport in Porous Media, 98 (2013) 35-57.

[25] N. Dukhan, O. Bagci, M. Ozdemir, “Thermal development in open-cell metal foam: An experiment with constant wall heat flux", International Journal of Heat and Mass Transfer, 85 (2015) 825-859. 


\section{List of figures:}

Fig. 1. Schematic of the computational domain

Fig. 2. Different positions for porous insert in the heat exchanger

Fig. 3. a) Typical grid used in the domain; b) Variations of overall heat transfer coefficient with number of grids for case (a) (grid independence study) at $D a=10^{-4}$ and $k_{r}=100$

Fig. 4. a) Comparison between the current results and analytical data reported by Ucar et al. [20] for axial velocity profile in a duct partially filled by a porous layer; b) Comparison between the current results and experimental data reported by Dukhan et al. [21] for local Nusselt number in a tube filled by porous material

Fig. 5. a) and b) Normalized velocity profile for all porous layer positions at $\mathrm{Da}=10^{-4}$ and $\mathrm{x}=\mathrm{L} / 2$; c) Normalized velocity profile for position of case (c) at $\mathrm{x}=\mathrm{L} / 2$ and two values of Darcy number

Fig. 6. Variations of pressure drop ratio with Darcy numbers for all porous layer positions

Fig. 7. Variations of overall heat transfer coefficient ratio with a) Darcy numbers at $k_{r}=100$ and b) thermal conductivity ratio at $\mathrm{Da}=10^{-4}$ for all porous layer positions

Fig. 8. Thermal entropy generation contours for all porous layer positions at $k_{r}=100$ and $\mathrm{Da}=10^{-4}$

Fig. 9. Viscous entropy generation contours for all porous layer positions at $\mathrm{k}_{\mathrm{r}}=100$ and $\mathrm{Da}=10^{-4}$

Fig. 10. Variations of thermal entropy generation ratio with a) Darcy numbers at $k r=100$ and b) thermal conductivity ratio at $\mathrm{Da}=10^{-4}$ for all porous layer positions; c) Variations of viscous entropy generation ratio with Darcy numbers for cases (a) and (b)

\section{List of tables:}

Table 1: Values of geometric parameters and thermal conditions

Table 2: Porous layers locations for both inner and outer tubes 


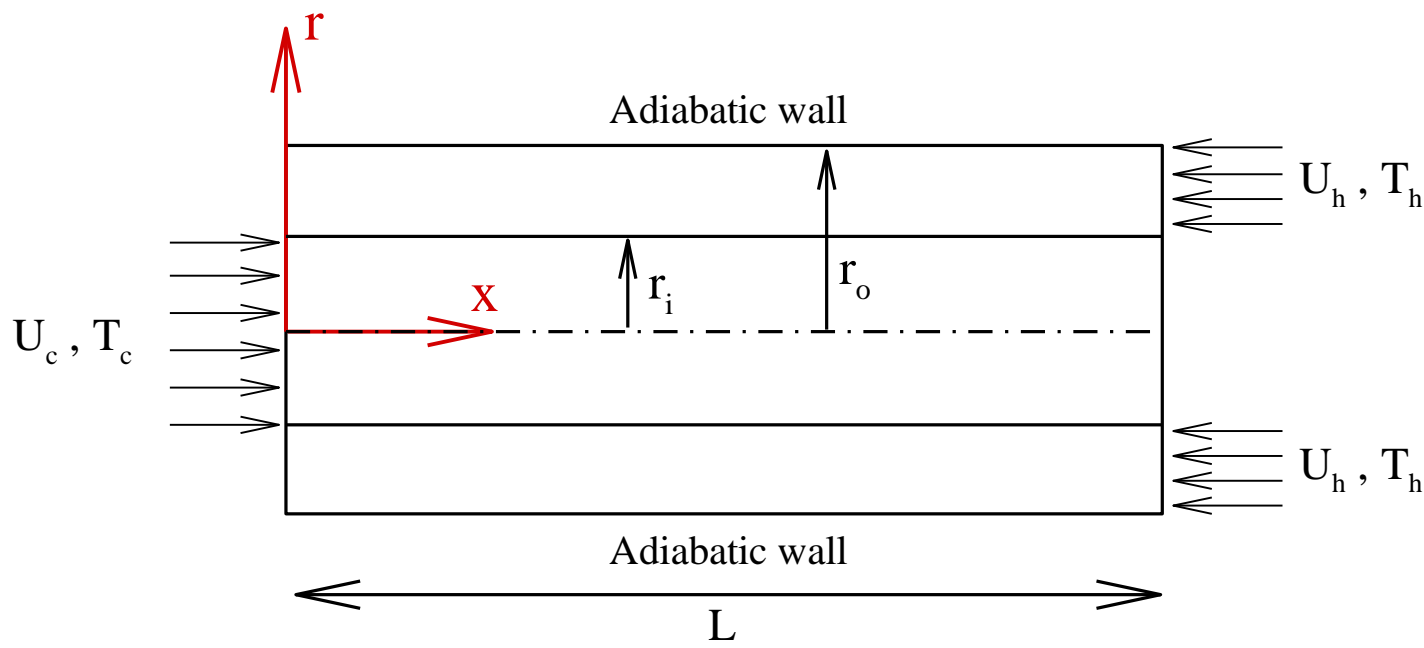

Fig. 1. Schematic of the computational domain 


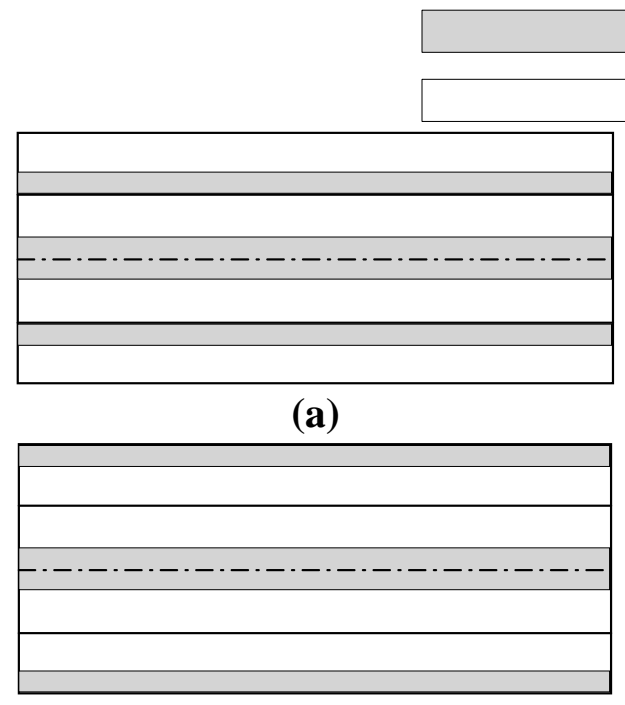

(c)
Porous zone

Clear zone

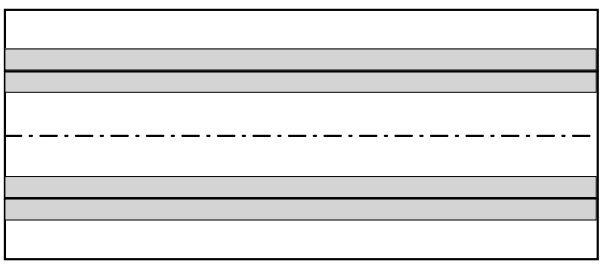

(b)

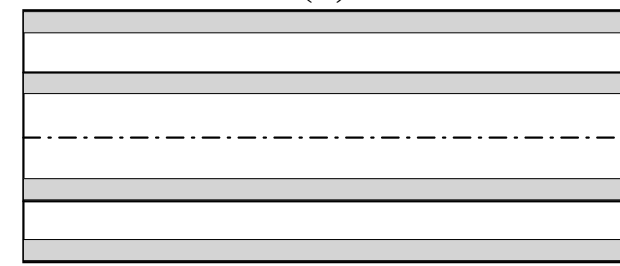

(d)

Fig. 2. Different positions for porous insert in the heat exchanger 


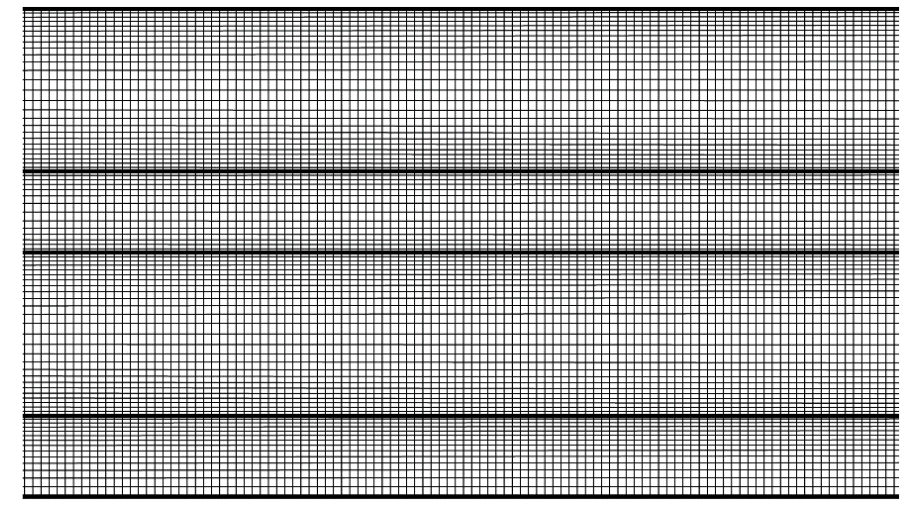

(a)

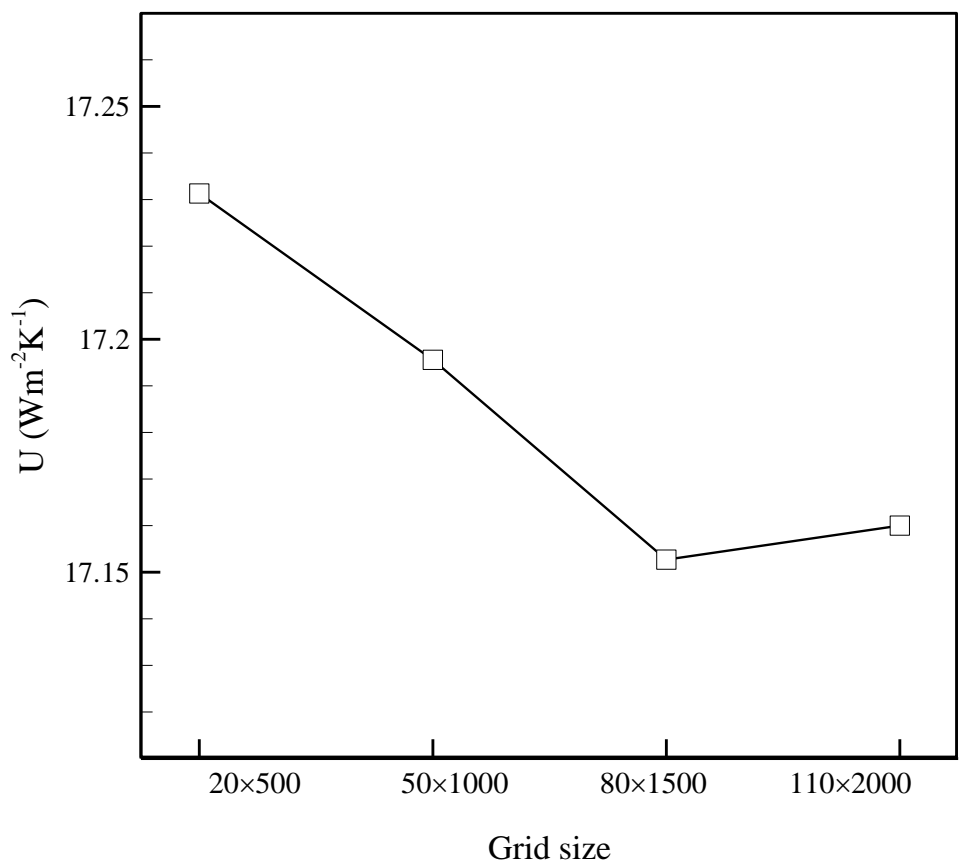

(b)

Fig. 3. a) Typical grid used in the domain; b) Variations of overall heat transfer coefficient with number of grids for case (a) (grid independence study) at $D a=10^{-4}$ and $k_{r}=100$ 
(a)
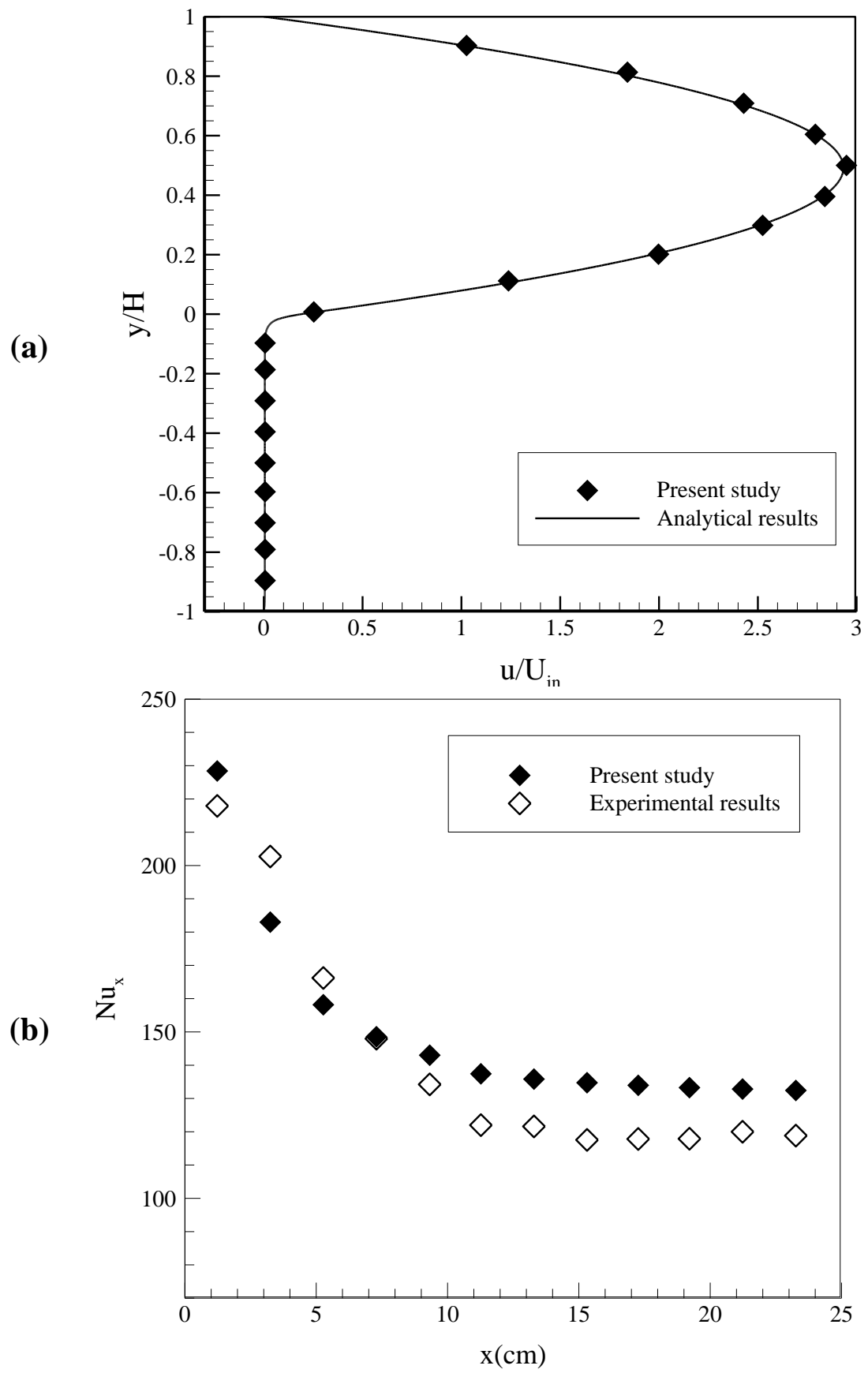

Fig. 4. a) Comparison between the current results and analytical data reported by Ucar et al. [24] for axial velocity profile in a duct partially filled by a porous layer; b) Comparison between the current results and experimental data reported by Dukhan et al. [25] for local Nusselt number in a tube filled by porous material 


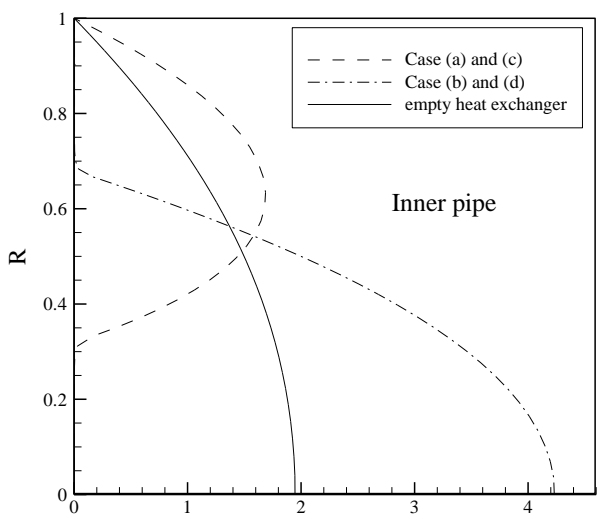

(a)

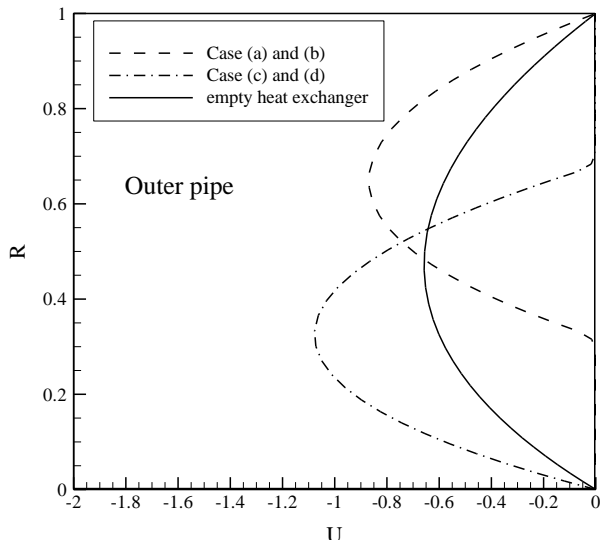

(b)

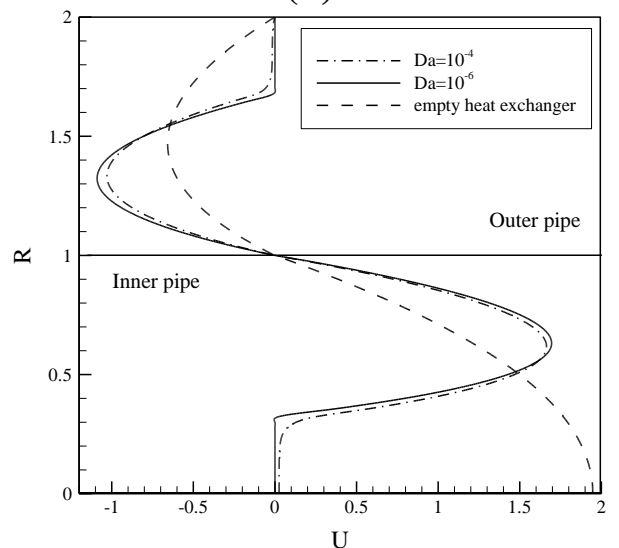

(c)

Fig. 5. a) and b) Normalized velocity profile for all porous layer positions at $\mathrm{Da}=10^{-4}$ and $\mathrm{x}=\mathrm{L} / 2$; c) Normalized velocity profile for position of case (c) at $\mathrm{x}=\mathrm{L} / 2$ and two values of Darcy number 


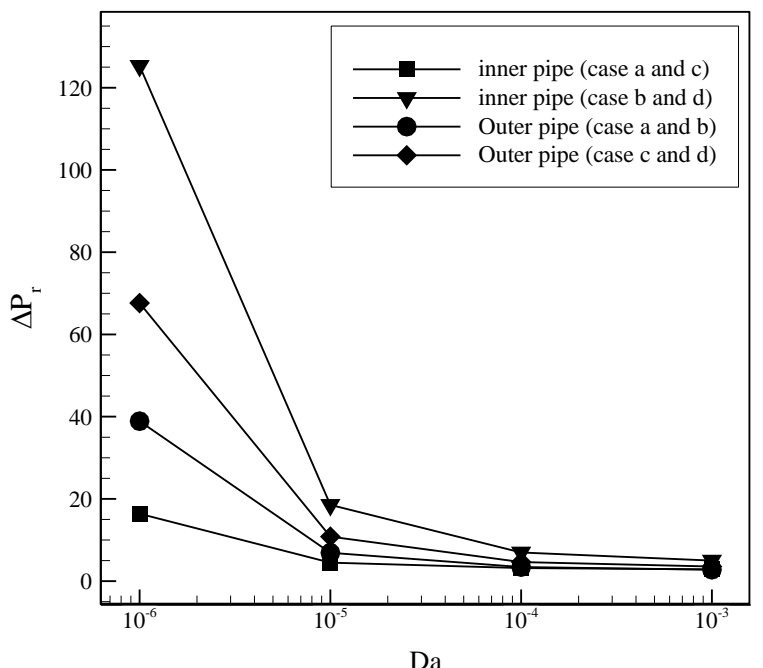

Fig. 6. Variations of pressure drop ratio with Darcy numbers for all porous layer positions 


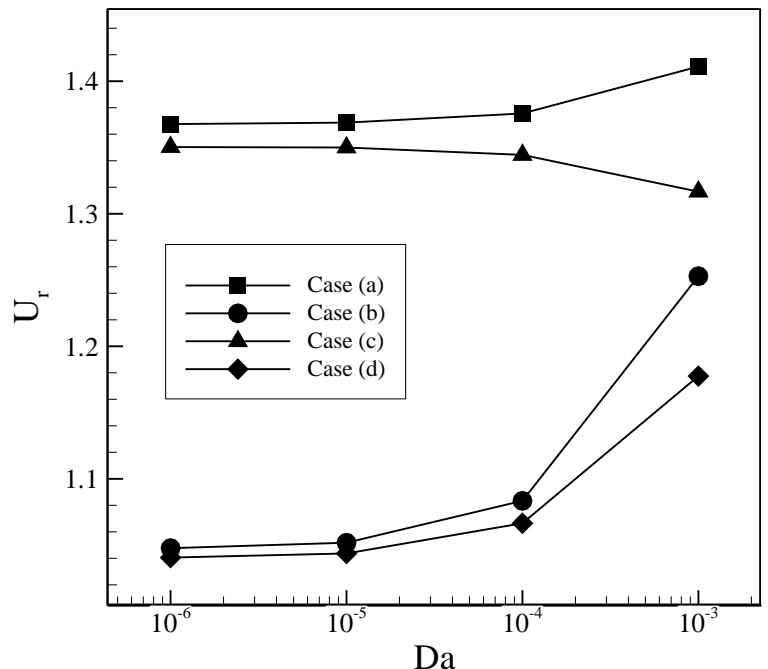

(a)

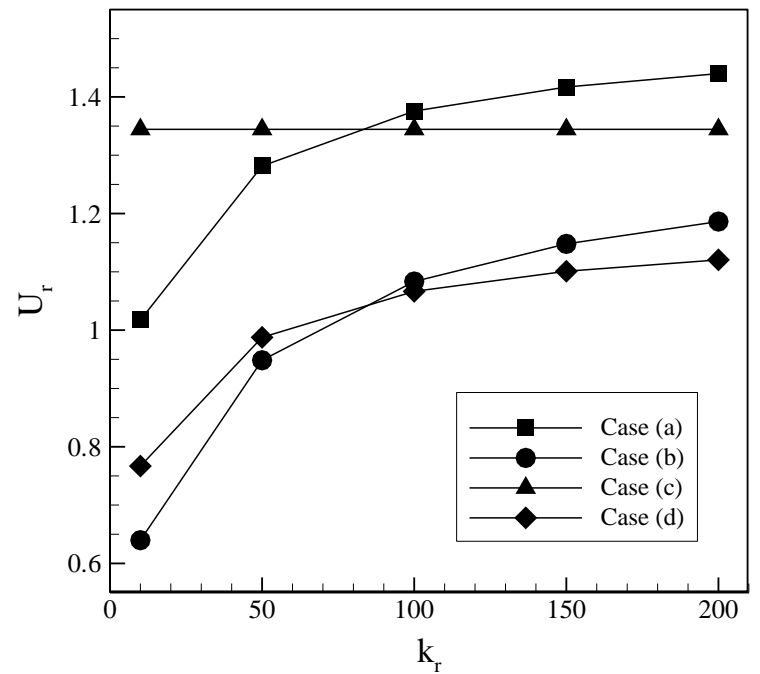

(b)

Fig. 7. Variations of overall heat transfer coefficient ratio with a) Darcy numbers at $\mathrm{k}_{\mathrm{r}}=100$ and b) thermal conductivity ratio at $\mathrm{Da}=10^{-4}$ for all porous layer positions 

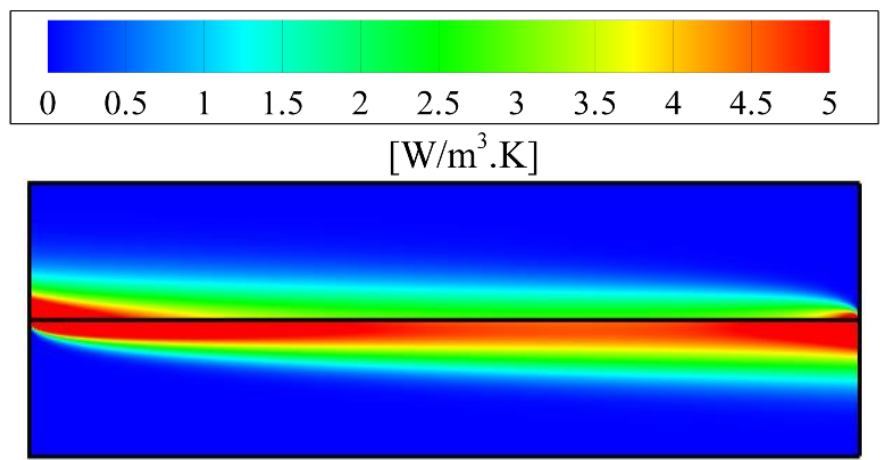

unfilled heat exchanger

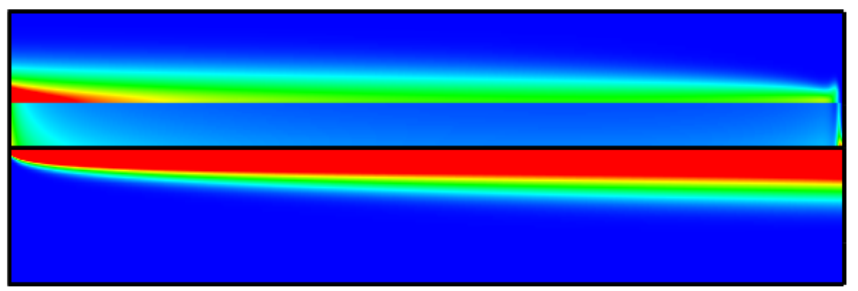

(a)

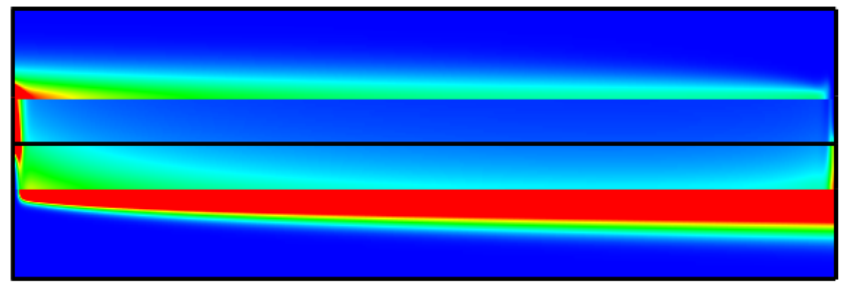

(b)

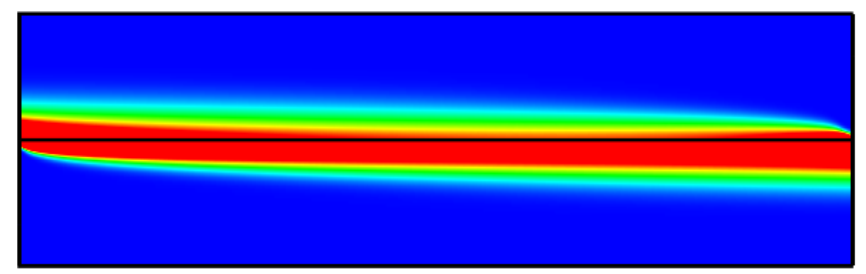

(c)

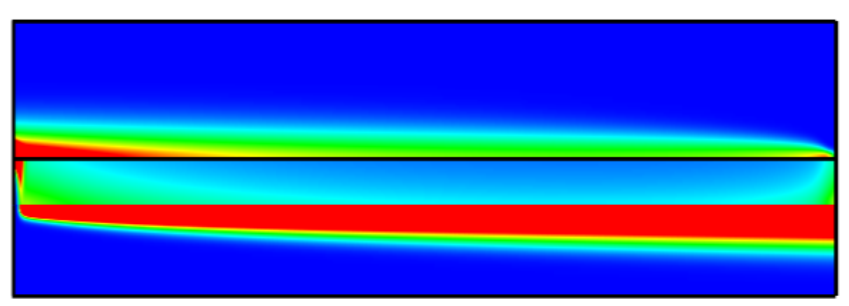

(d)

Fig. 8. Thermal entropy generation contours for all porous layer positions at $\mathrm{k}_{\mathrm{r}}=100$ and

$$
\mathrm{Da}=10^{-4}
$$




\begin{tabular}{|l|}
\hline $\left.\mathrm{W} / \mathrm{m}^{3} \cdot \mathrm{K}\right]$ \\
\hline $5.5 \mathrm{E}-08$ \\
$4 \mathrm{E}-08$ \\
$3.5 \mathrm{E}-08$ \\
$3 \mathrm{E}-08$ \\
$2.5 \mathrm{E}-08$ \\
$2 \mathrm{E}-08$ \\
$1.5 \mathrm{E}-08$ \\
$1 \mathrm{E}-08$ \\
$5 \mathrm{E}-09$ \\
0
\end{tabular}

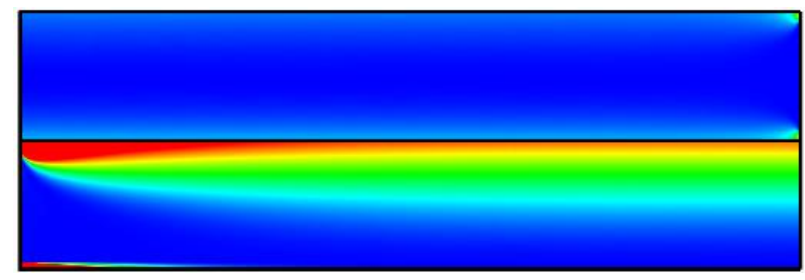

unfilled heat exchanger

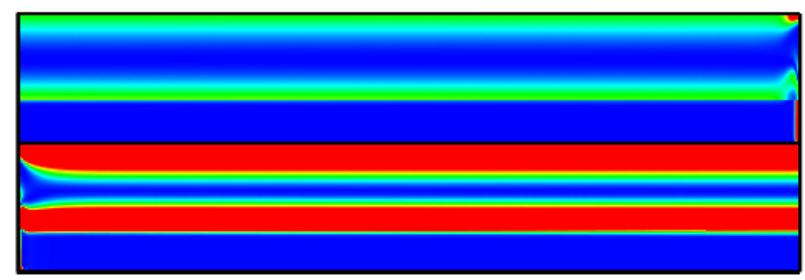

(a)

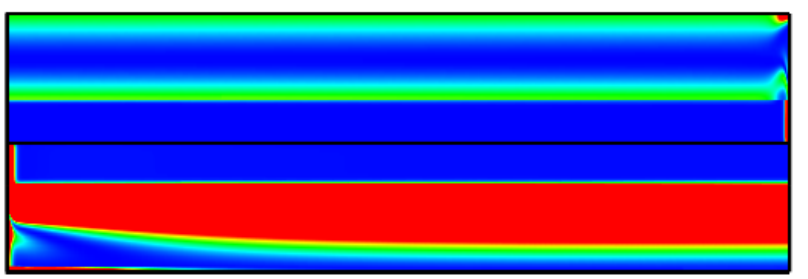

(b)

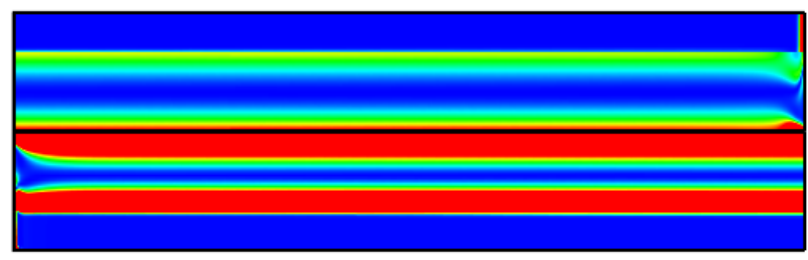

(c)

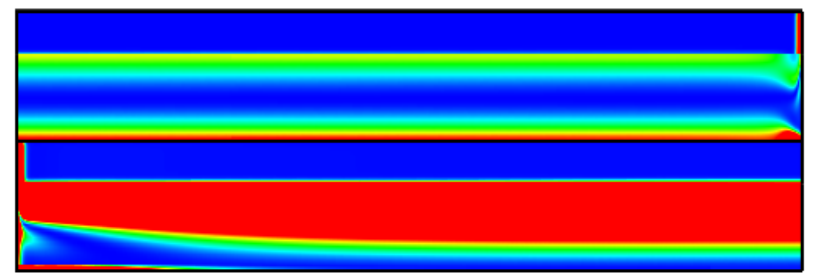

(d)

Fig. 9. Viscous entropy generation contours for all porous layer positions at $k_{r}=100$ and

$$
\mathrm{Da}=10^{-4}
$$




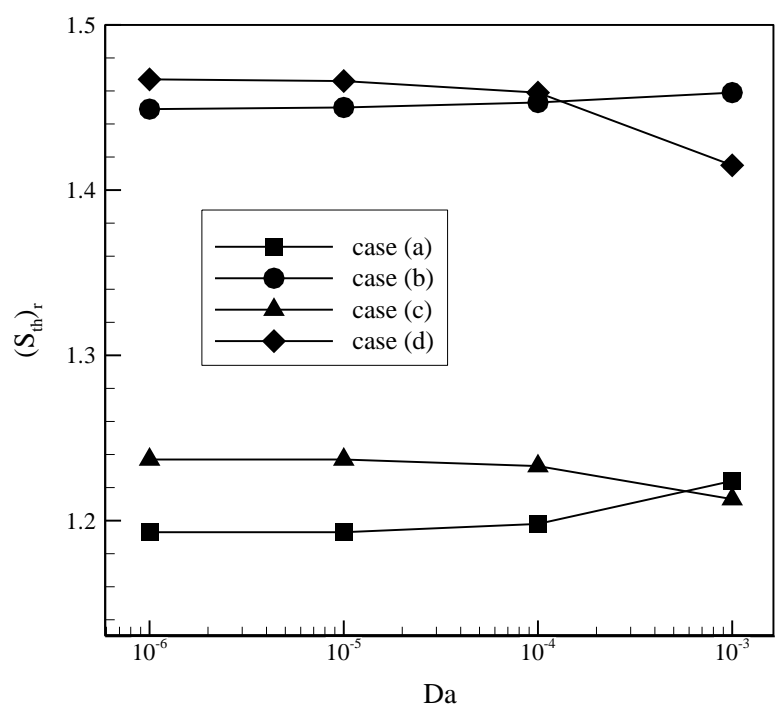

(a)

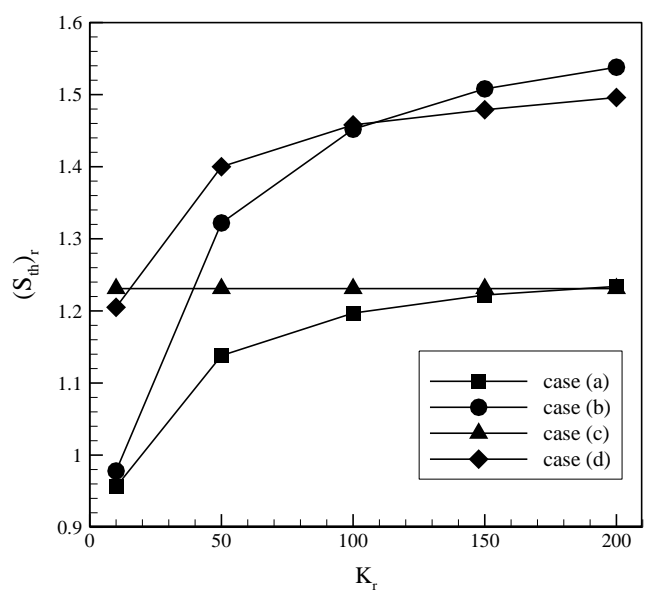

(b)

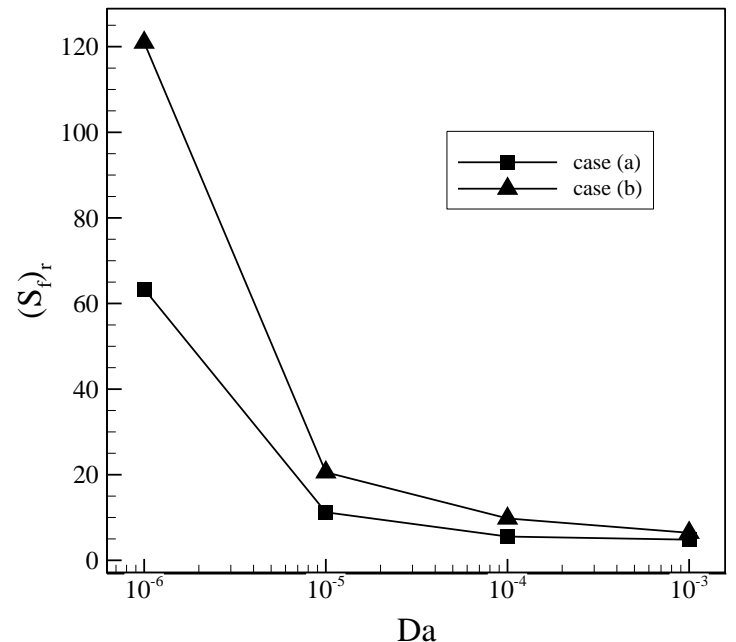

(c)

Fig. 10. Variations of thermal entropy generation ratio with a) Darcy numbers at $\mathrm{kr}=100$ and b) thermal conductivity ratio at $\mathrm{Da}=10^{-4}$ for all porous layer positions; c) Variations of viscous entropy generation ratio with Darcy numbers for cases (a) and (b) 
Table 1: Values of geometric parameters and thermal conditions

\begin{tabular}{|c|c|c|}
\hline$r_{i}=9 \mathrm{~cm}$ & $r_{o}=2 r_{i}$ & $L=100 r_{i}$ \\
\hline$T_{c}=300 \mathrm{~K}$ & $T_{h}=350 \mathrm{~K}$ & $S=\frac{1}{3} D_{h}$ \\
\hline
\end{tabular}

Table 2: Porous layers locations for both inner and outer tubes

\begin{tabular}{ccc}
\hline Case & Inner tube & Outer tube \\
\hline$a$ & Core & Inner wall \\
\hline$b$ & wall & Inner wall \\
\hline$c$ & Core & Outer wall \\
\hline$d$ & wall & Outer wall
\end{tabular}

